\title{
Cadmium Alters the Concentration of Fatty Acids in THP-1 Macrophages
}

\author{
Tomasz Olszowski $^{1}$ - Izabela Gutowska ${ }^{2}$ - Irena Baranowska-Bosiacka ${ }^{3}$. \\ Agnieszka Lukomska $^{2}$ - Arleta Drozd ${ }^{2}$ - Dariusz Chlubek ${ }^{3}$
}

Received: 28 February 2017 / Accepted: 5 June 2017 /Published online: 10 June 2017

(C) The Author(s) 2017. This article is an open access publication

\begin{abstract}
Fatty acid composition of human immune cells influences their function. The aim of this study was to evaluate the effects of known toxicant and immunomodulator, cadmium, at low concentrations on levels of selected fatty acids (FAs) in THP-1 macrophages. The differentiation of THP-1 monocytes into macrophages was achieved by administration of phorbol myristate acetate. Macrophages were incubated with various cadmium chloride $\left(\mathrm{CdCl}_{2}\right)$ solutions for $48 \mathrm{~h}$ at final concentrations of $5 \mathrm{nM}, 20 \mathrm{nM}, 200 \mathrm{nM}$, and $2 \mu \mathrm{M}$ $\mathrm{CdCl}_{2}$. Fatty acids were extracted from samples according to the Folch method. The fatty acid levels were determined using gas chromatography. The following fatty acids were analyzed: long-chain saturated fatty acids (SFAs) palmitic acid and stearic acid, very long-chain saturated fatty acid (VLSFA) arachidic acid, monounsaturated fatty acids (MUFAs) palmitoleic acid, oleic acid and vaccenic acid, and $n-6$ polyunsaturated fatty acids (PUFAs) linoleic acid and arachidonic acid. Treatment of macrophages with very low concentrations of cadmium (5-200 nM) resulted in significant reduction in the levels of arachidic, palmitoleic, oleic, vaccenic, and linoleic acids and significant increase in arachidonic acid levels (following exposure to $5 \mathrm{nM} \mathrm{Cd}$ ), without significant reduction of palmitic and stearic acid levels. Treatment of
\end{abstract}

Irena Baranowska-Bosiacka irena.bosiacka@pum.edu.pl

1 Department of Hygiene and Epidemiology, Pomeranian Medical University, Powstańców Wlkp. 72 Str, 70-111 Szczecin, Poland

2 Department of Biochemistry and Human Nutrition, Pomeranian Medical University, Broniewskiego 24 Str, 71-460 Szczecin, Poland

3 Department of Biochemistry and Medical Chemistry, Pomeranian Medical University, Powstańców Wlkp. 72 Str,

70-111 Szczecin, Poland macrophages with the highest tested cadmium concentration $(2 \mu \mathrm{M})$ produced significant reduction in the levels of all examined FAs: SFAs, VLSFA, MUFAs, and PUFAs. In conclusion, cadmium at tested concentrations caused significant alterations in THP-1 macrophage fatty acid levels, disrupting their composition, which might dysregulate fatty acid/lipid metabolism thus affecting macrophage behavior and inflammatory state.

Keywords Cadmium · Fatty acids $\cdot$ THP-1 macrophages

\section{Introduction}

Fatty acids (FAs) play multiple roles in immune cells, including serving as fuels for energy generation, contributing to physical and functional properties of cell membranes (as components of cell membrane phospholipids), or being covalent modifiers of protein structure. Fatty acids are also regulators of gene expression acting either on receptor activity, intracellular signaling, or transcription factor activation. Moreover, FAs are precursors for synthesis of bioactive lipid mediators, such as prostaglandins, leukotrienes, lipoxins, and resolvins [1]. Fatty acid composition of human immune cells influences their function via a variety of ways, including membrane alterations, effects on signal transduction pathways, or alterations in lipid mediators' patterns [1].

A number of studies, both in vivo and in vitro, examined the effects of enrichment with different fatty acids on fatty acid profile in different cells, on cell function and behavior, and/or on different processes, such as inflammation [1-11].

Long-chain saturated fatty acids (SFAs), such as palmitic acid and stearic acid, have been found to produce a proinflammatory effect on several cell types, including human 
macrophages, inducing different inflammatory pathways [5, $9,10]$.

Very long-chain saturated fatty acids (VLSFAs), such as arachidic acid, play an important role in normal physiology. They are components of sphingolipids, such as sphingomyelin and ceramides, and impart specific biological activities to the sphingolipids. There is growing evidence that circulating VLSFAs, in contrast to long-chain SFAs, may have beneficial biological properties [12].

The monounsaturated fatty acids (MUFAs) palmitoleic acid and oleic acid are the products of stearoyl-CoA desaturase (SCD), known also as $\triangle 9$-desaturase, the enzyme catalyzing biosynthesis of MUFAs from SFAs. The abovementioned MUFAs are the most abundant MUFAs of phospholipids, triglycerides, and cholesteryl esters. MUFAs may also act as mediators of signal transduction and cellular differentiation. Changes in SCD activity and in the balance between SFAs and MUFAs might have an effect in various diseases including cancer, diabetes, atherosclerosis, and obesity [13]. Oleic acid may have the ability to impede and reverse SFA-induced inflammation [11]. Oral administration of oleic acid decreased production of inflammatory mediators by rat macrophages [8].

Vaccenic acid is a ruminant-derived trans-fat and precursor of conjugated linoleic acid (CLA). Enrichment of diet of JCR:LA-cp rats (a rodent model of metabolic syndrome) with vaccenic acid has been shown to exert beneficial effects on lipids and lipoproteins [3]. In another study, vaccenic acid was demonstrated to decrease the pro-inflammatory markers IL-2 and TNF- $\alpha$ in this rat strain. However, such effect was not observed in normal rats, suggesting that the efficacy of vaccenic acid to benefit CVD might be more profound under disease conditions $[4,14]$.

The $n-6$ polyunsaturated fatty acid (PUFA) linoleic acid was demonstrated to blunt LPS-induced inflammation in THP-1 macrophages [2]. Oral administration of linoleic acid decreased the production of IL-1 $\beta$, IL-6, IL-10, and VEGF in rat macrophages [8]. Linoleic acid can be converted to $\gamma$ linolenic acid and arachidonic acid. The $n-6$ PUFA arachidonic acid is the major substrate for the synthesis of eicosanoids, such as prostaglandins, leukotrienes, and other oxidized derivatives [15]. Enrichment of THP-1 macrophages with arachidonic acid was found to exert inhibitory effect on transcriptional levels of inflammatory factors and their secretion in culture media [6].

Cadmium is a well-known toxicant and immunomodulatory factor $[16,17]$, inducing inflammation in different biological systems [18-20]. It has been found that oxidative stress has been implicated in cadmium toxicity. Free radical induction by cadmium (i.e., superoxide anion, hydrogen peroxide, hydroxyl radical, and lipid radicals) appears to be a key factor responsible for its immunotoxic action [21]. Since cadmium is a redox-inactive metal, some indirect mechanisms, such as disruption of cellular antioxidant systems, inflammation, and involvement of iron for the Fenton reaction, must mediate free radical generation by cadmium [21]. In one of our previous studies, we examined one of the possible mechanisms involved in inflammatory reaction of THP-1 macrophages exposed to low concentrations of cadmium for $48 \mathrm{~h}$ : cadmium effects on COX-1 and COX-2 at messenger RNA (mRNA), protein, and enzymatic activity levels [22]. We demonstrated that cadmium at the highest tested concentration $(2 \mu \mathrm{M})$ induced expression of COX-1 and COX-2 at the mRNA level, but not at the protein or enzymatic activity levels. In our another study, we observed increased ROS generation by all tested cadmium concentrations following 48-h exposure [23], which might contribute to COX-2 induction [24].

Several studies investigated the influence of cadmium on fatty acid and/or lipid metabolism in different experimental models $[18,19,25-37]$. The vast majority of those studies demonstrated significant alterations in fatty acid composition and/or fatty acid/lipid metabolism induced by cadmium. However, to the best of our knowledge, there was no study investigating the effects of cadmium on fatty acids in human immune cells. Cadmium-induced alterations in concentrations of fatty acids, such as arachidonic acid, being the precursors of products of cyclooxygenases activity (i.e., prostaglandin E2 and thromboxane B2), might play a key role in mechanisms of cadmium action in THP-1 macrophages described in our previous papers $[22,23]$. Therefore, the aim of this study was to examine the effects of cadmium at low concentrations on the levels of selected fatty acids in THP-1 macrophages.

\section{Material and Methods}

\section{Cell Culture and Treatment}

The experiments were carried out on THP-1-derived macrophages. Human monocytic leukemia cell line THP-1 (American Type Culture Collection, Rockville, MD, USA) was selected, a widely used in vitro model for the investigation of the molecular mechanisms behind monocyte-tomacrophage differentiation [38]. THP-1 cells, seeded in an amount of about $2.5 \times 10^{6}$ cells/well in 6-well plates, were induced to differentiate into macrophages by treatment with $100 \mathrm{nM}$ phorbol myristate acetate (PMA) for $24 \mathrm{~h}$. The next step was washing the adherent macrophages three times with PBS followed by 48 -h culture (at $37^{\circ} \mathrm{C}$ in $5 \% \mathrm{CO}_{2}$ ) in medium containing $10 \%$ of FBS (fetal bovine serum; Gibco, Paisley, UK), penicillin (100 U/mL), streptomycin (100 mg/ $\mathrm{mL}$ ), and cadmium chloride $\left(\mathrm{CdCl}_{2}\right)$. In this study, $5 \mathrm{nM}$, $20 \mathrm{nM}, 200 \mathrm{nM}$, and $2 \mu \mathrm{M}$ cadmium chloride concentrations were applied, since they corresponded to the cadmium level range detected in human blood due to environmental or occupational exposure [22, 39]. After incubation with cadmium, 
the cells were harvested by scraping and centrifuged $(800 \times g$, $10 \mathrm{~min}$ ) to obtain pellets.

The trypan blue staining was used to determine the percent of viable cells using the Bright Line Hemacytometer (SigmaAldrich, Poznań, Polska). A cell cultures' viability higher than $97 \%$ in the control group was the criterion of their use for experiments [40].

The experiments were conducted in six separate assays (each assay in three replicates).

\section{Extraction of Fatty Acids}

The extraction of fatty acids from samples was performed according to the Folch method [41]. Fatty acids were protected against the oxidation reaction by the addition of $0.5 \%$ BHT solution to each sample. In a further step, the saponification of the samples was carried out with $1 \mathrm{~mL}$ of $2 \mathrm{M}$ $\mathrm{KOH}$ methanolic solution at $70{ }^{\circ} \mathrm{C}$ for $20 \mathrm{~min}$, followed by the methylation with $1 \mathrm{~mL}$ of $14 \%$ solution of boron trifluoride in methanol under the same conditions. Next, there was addition of $1 \mathrm{~mL}$ of $n$-hexane and $10 \mathrm{~mL}$ of saturated $\mathrm{NaCl}$ solution. After mixing, $1 \mathrm{~mL}$ of the $n$-hexane phase was collected for analysis.

\section{Analysis of Fatty Acids}

Fatty acid concentrations were determined by gas chromatography using the Agilent Technologies 7890A GC System (SUPELCOWAX ${ }^{\mathrm{TM}} 10$ Capillary GC Column $(15 \mathrm{~m} \times 0.10 \mathrm{~mm}, 0.10 \mu \mathrm{m})$ ) (Supelco, Bellefonte, PA, USA). The following chromatographic conditions were applied: the initial temperature of $60^{\circ} \mathrm{C}$ for $0 \mathrm{~min}$, increased at a rate of $40{ }^{\circ} \mathrm{C} / \mathrm{min}$ to $160{ }^{\circ} \mathrm{C}(0 \mathrm{~min})$, increased at a rate of $30^{\circ} \mathrm{C} / \mathrm{min}$ to $190^{\circ} \mathrm{C}(1 \mathrm{~min})$, and then increased at a rate of $30{ }^{\circ} \mathrm{C} / \mathrm{min}$ to $230^{\circ} \mathrm{C}$ for $2.6 \mathrm{~min}$, where it was maintained for $4.9 \mathrm{~min}$. The total analysis took approximately $8 \mathrm{~min}$. The gas flow rate was $0.8 \mathrm{~mL} / \mathrm{min}$; the carrier gas comprised of hydrogen. The identification of fatty acids was done by comparing their retention times with those of commercially available standards.

The fatty acid concentrations were determined based on standard curves and were expressed in milligrams per milliliter.

\section{Determination of Protein Concentration}

Protein concentration was measured using a Micro BCA Protein Assay Kit (Thermo Scientific, Pierce Biotechnology, USA) and spectrophotometer (UVM340, ASYS). The bicinchoninic acid (BCA) protein assay was performed according to the manufacturer's instructions [42].

\section{Statistical Analysis}

For all quantitative parameters, the arithmetical means and the standard deviations $( \pm \mathrm{SD})$ were presented. The normality of data for individual variables was assessed using the ShapiroWilk test. Since most of the distributions deviated from normality, the non-parametric tests were applied for further analyses. Wilcoxon matched-pairs test was applied to evaluate the differences between the concentrations of cadmium used. In order to assess the association between cadmium and fatty acid levels in THP-1 macrophages, Spearman's correlation coefficients $(R)$ and $p$ values were calculated. The obtained results were processed using Statistica 10 (StatSoft, Poland) software. Levels of $p<0.05$ were considered as statistically significant.

\section{Results}

The results of the study are presented in Figs. 1, 2, 3, 4, 5, 6, 7, and 8. Exposure to cadmium chloride at a concentration of $2 \mu \mathrm{M}$ for $48 \mathrm{~h}$ caused significant reduction of concentration of palmitic acid in THP-1 macrophages. The exposure to lower tested cadmium concentrations $(5,20$, and $200 \mathrm{nM})$ did not result in significant changes in palmitic acid concentrations, relative to controls (Fig. 1).

Similar effects of cadmium were found on stearic acid: $2 \mu \mathrm{M} \mathrm{Cd}$ resulted in significantly decreased, relative to controls, stearic acid concentration in macrophages (Fig. 2).

Cadmium at concentrations of $20 \mathrm{nM}, 200 \mathrm{nM}$, and $2 \mu \mathrm{M}$ markedly decreased the concentrations of arachidic acid in macrophages as compared to controls (Fig. 3).

THP-1 macrophages treated with $20 \mathrm{nM}, 200 \mathrm{nM}$, and $2 \mu \mathrm{M} \mathrm{Cd}$ exhibited significantly lower (relative to controls) concentrations of palmitoleic acid (Fig. 4).

The other MUFA, oleic acid, concentration appeared to be significantly reduced in macrophages exposed to $5 \mathrm{nM}$, $20 \mathrm{nM}$, and $2 \mu \mathrm{M}$ cadmium as compared to controls (Fig. 5).

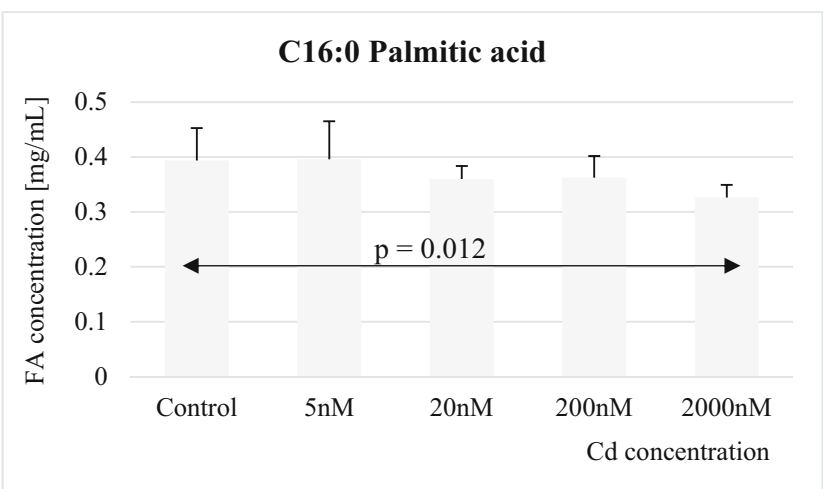

Fig. 1 Influence of Cd on palmitic acid (C16:0) concentration in THP-1 macrophages 


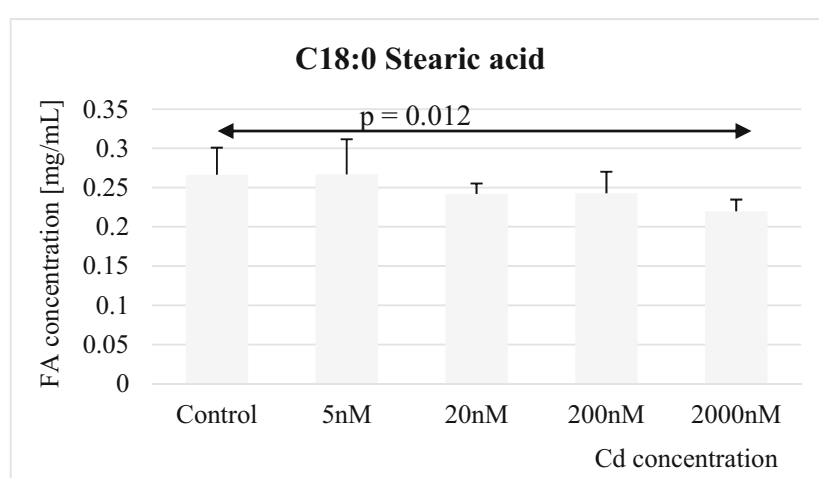

Fig. 2 Influence of $\mathrm{Cd}$ on stearic acid (C18:0) concentration in THP-1 macrophages

The concentration of vaccenic acid was significantly reduced in macrophages cultured with $20 \mathrm{nM}, 200 \mathrm{nM}$, and $2 \mu \mathrm{M}$ cadmium chloride as compared to controls (Fig. 6).

Exposure to cadmium at concentrations $5 \mathrm{nM}$ and $2 \mu \mathrm{M}$ resulted in significant decrease in linoleic acid levels in THP-1 macrophages, as compared to controls (Fig. 7).

The effect of cadmium on arachidonic acid was biphasic depending on cadmium concentration: very low cadmium concentrations (i.e., $5 \mathrm{nM}$ ) appeared to increase markedly arachidonic acid levels, while the highest tested cadmium concentration $(2 \mu \mathrm{M})$ resulted in significant reduction of arachidonic acid levels compared to control macrophage cultures (Fig. 8).

The analysis of correlation revealed negative correlation between the fatty acid content and cadmium concentration in the macrophage culture. Moderate negative correlation was found between cadmium and arachidic acid $(R=-0.67$; $p=0.00007)$ and between cadmium and vaccenic acid $(R=-0.65 ; p=0.0001)$, while low negative correlation was demonstrated between cadmium and stearic acid $(R=-0.49$; $p=0.007)$ and between cadmium and oleic acid $(R=-0.48$; $p=0.009)$.

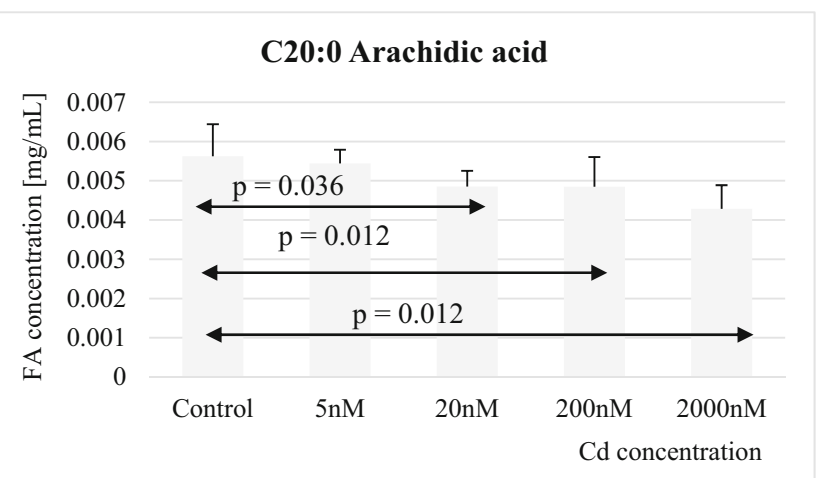

Fig. 3 Influence of $\mathrm{Cd}$ on arachidic acid (C20:0) concentration in THP-1 macrophages

\section{C16:1 Palmitoleic acid}

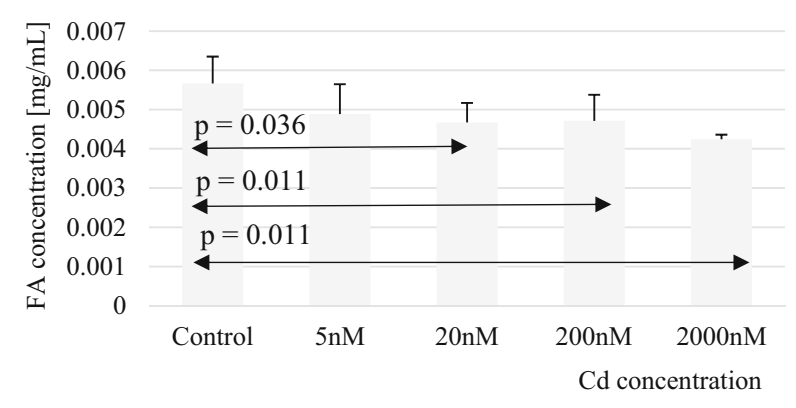

Fig. 4 Influence of $\mathrm{Cd}$ on palmitoleic acid (C16:1) concentration in THP-1 macrophages

\section{Discussion}

Cadmium is a well-known immunomodulatory factor [16, 17]. This study is a continuation of our previous studies which main aim was to describe some biochemical and molecular mechanisms of toxicity of cadmium (at low concentrations) in THP-1 macrophages (the effects on COXs, ROS, and apoptosis) using the same experimental conditions (i.e., cadmium concentrations of $5 \mathrm{nM}, 20 \mathrm{nM}, 200 \mathrm{nM}$, and $2 \mu \mathrm{M}, 48-\mathrm{h}$ Cd exposure) [22, 23]. Mitochondria constitute important targets of cadmium toxicity [43]. The following sequence of events has been proposed to occur in mitochondria as a result of cadmium action: cadmium binding to protein thiols in mitochondrial membrane affecting mitochondrial permeability transition, inhibition of respiratory chain reaction, and then generation of ROS [44]. Cadmium was shown to cause disturbances in functioning of complex III of the electron transfer chain (i.e., inhibition of that complex) resulting in the increase in ROS generation [ 43,45$]$. In one of our previous studies, we demonstrated decreased mitochondrial membrane potential and increased mitochondrial ROS generation in THP-1 macrophages cultured with all tested cadmium concentrations ( $5 \mathrm{nM}, 20 \mathrm{nM}, 200 \mathrm{nM}$, and $2 \mu \mathrm{M}$ ) for $48 \mathrm{~h}$ [23]. In the present

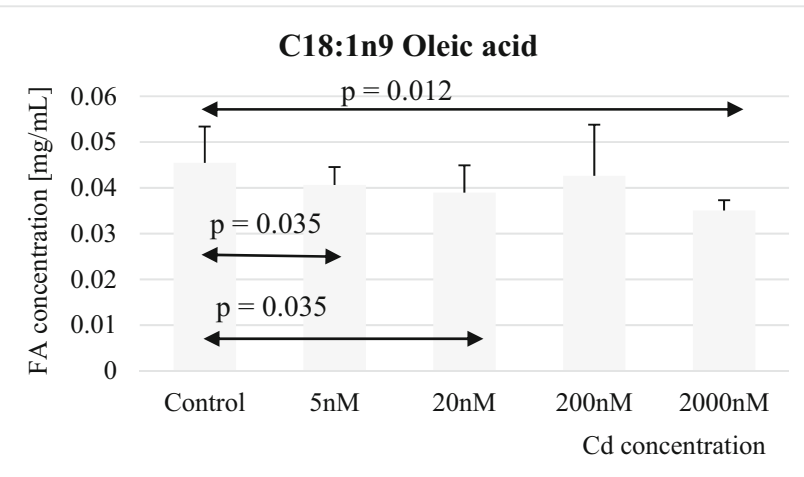

Fig. 5 Influence of Cd on oleic acid (C18:1n9) concentration in THP-1 macrophages 


\section{C18:1 trans Vaccenic acid}

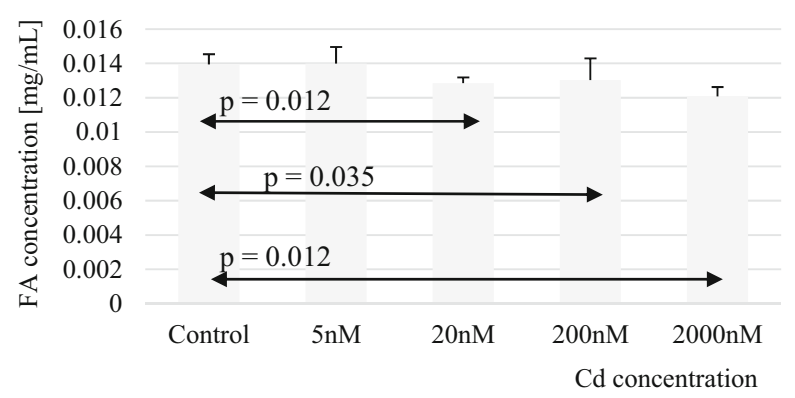

Fig. 6 Influence of Cd on trans vaccenic acid (C18:1) concentration in THP-1 macrophages

study, we wanted to test whether cadmium modifies the fatty acid profile in THP-1 macrophages. We demonstrated that macrophages exposed to cadmium exhibited marked alterations in the levels of analyzed fatty acids. Treatment of macrophages with very low concentrations of cadmium (5$200 \mathrm{nM}$ ) resulted in significant reduction in the levels of arachidic, palmitoleic, oleic, vaccenic, and linoleic acids and significant increase in arachidonic acid levels (following exposure to $5 \mathrm{nM} \mathrm{Cd}$ ), without significant reduction of palmitic and stearic acid levels. Treatment of macrophages with the highest tested cadmium concentration $(2 \mu \mathrm{M})$ for $48 \mathrm{~h}$ produced significant reduction in the levels of all examined FAs: SFAs, VLSFA, MUFAs, and PUFAs.

Similar results were obtained by Steibert and Kokot in a different experimental model: the authors demonstrated that fatty acid biosynthesis was significantly inhibited in cytoplasmic fraction of hepatocytes of Wistar rats treated with $0.25 \mathrm{mg}$ $\mathrm{Cd} / \mathrm{kg}$ body wt. or higher doses for 20 days as compared to controls [46].

Regarding the effects of Cd on SFA concentrations, our study results seem to be discordant to the results of Ramirez and Gimenez [30], Larregle et al. [34], Konar et al. [36], and Kudo et al. [26], who demonstrated increased proportions of

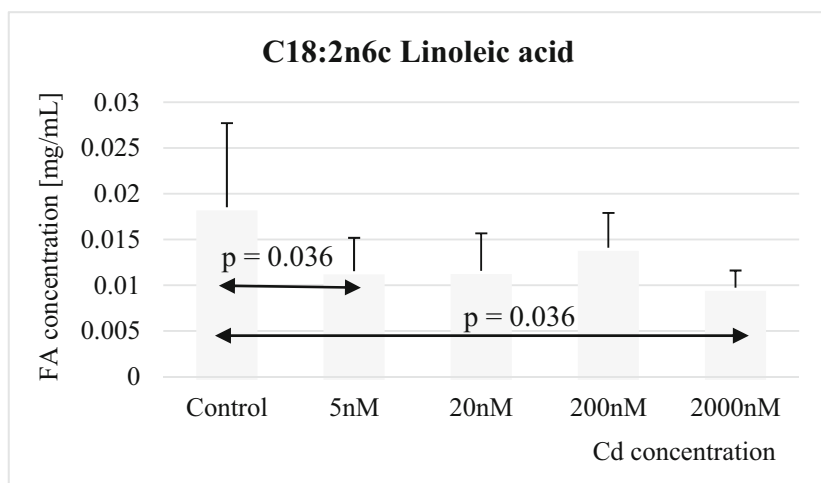

Fig. 7 Influence of $\mathrm{Cd}$ on linoleic acid $(\mathrm{C} 18: 2 \mathrm{n} 6 \mathrm{c})$ concentration in THP-1 macrophages

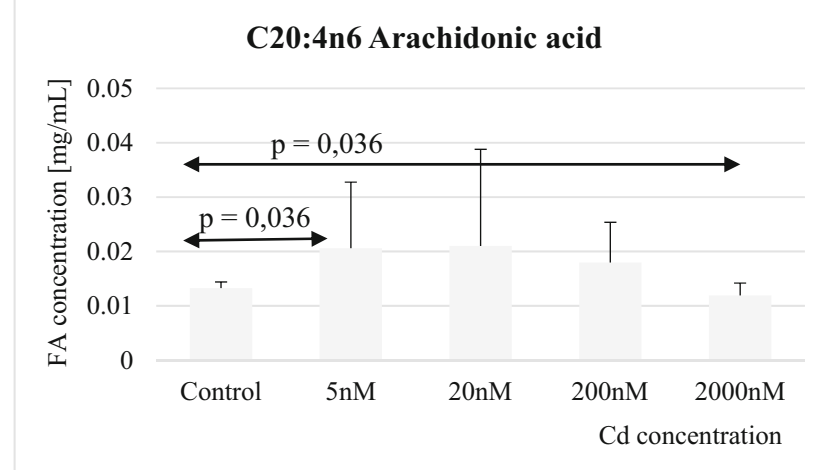

Fig. 8 Influence of $\mathrm{Cd}$ on arachidonic acid (C20:4n6) concentration in THP-1 macrophages

some SFAs due to cadmium treatment in different experimental systems. However, our study results seem to be in line with the results of Farid et al., who showed significant inhibitory effect of Cd on palmitate metabolism [25].

In our study, the effect of cadmium at most tested concentrations on MUFAs levels in macrophages was found to be inhibitory. Such result is in accordance with the findings of Kudo and Waku [28], Kudo and coworkers [47] and Ramirez and Gimenez [30], but in disagreement with the findings of Larregle and coworkers [34].

According to literature, cadmium was found to decrease MUFA:SFA ratio [30, 34], which reflects the cadmiuminduced inhibition of $\Delta 9$-desaturase [26, 28, 47]. We speculate that the lower tested cadmium concentrations might decrease MUFA:SFA ratio, because MUFA concentrations were significantly reduced without significant alteration of SFA concentrations. Taking this into consideration, cadmium might reduce $\Delta 9$-desaturase activity in our experimental model. Moreover, the results of correlation analysis might support this hypothesis: the inverse correlation between cadmium and stearic acid (the substrate of SCD enzyme) and between cadmium and oleic acid (the product of SCD enzyme).

Cadmium-disturbed MUFA:SFA ratio might influence different aspects of cell metabolism, and, for example, promote inflammation [48].

Exposure of THP-1 macrophages to $5 \mathrm{nM}$ and $2 \mu \mathrm{M} \mathrm{Cd}$ caused significant reduction of levels of linoleic acid. Such result is consistent with the study results of Larregle et al. [34] and Ramirez and Gimenez [30]. Significantly decreased concentration of linoleic acid in macrophages exposed to $5 \mathrm{nM} \mathrm{Cd}$ could be due to an increase of its conversion to arachidonic acid, which is catalyzed by delta- 6 desaturase, since the concentration of arachidonic acid was significantly elevated by this cadmium concentration.

Significantly increased arachidonic acid levels in macrophages following exposure to the lowest tested cadmium concentration $(5 \mathrm{nM})$ might be explained by cadmium-induced, diminished utilization of arachidonic acid by COXs as a substrate to prostaglandin and thromboxane synthesis. The results 
obtained in our previous study, i.e., the lack of significant alterations in mRNA and protein expression as well as enzymatic activity of COXs in THP- 1 macrophages exposed to $5 \mathrm{nM} \mathrm{Cd}$ for $48 \mathrm{~h}$ [22], seem to support the above supposition.

Another possible explanation for the increased arachidonic acid concentration by $5 \mathrm{nM} \mathrm{Cd}$ might be cadmium-induced increased activity of delta- 6 desaturase, catalyzing conversion of linoleic acid to arachidonic acid [28].

Treatment of THP-1 macrophages with $2 \mu \mathrm{M}$ cadmium resulted in significant decrease in the levels of arachidonic acid. Such result is consistent with the results obtained by Kudo et al. [27], but it is opposite the findings of Ramirez and coworkers [29], Ramirez and Gimenez [30], and Larregle and coworkers [34].

The decreased concentrations of MUFAs and PUFAs by $2 \mu \mathrm{M} \mathrm{Cd}$ may be due to metal induction of the cyclooxygenase pathway [49]. However, in one of our previous studies using the same experimental model and experimental conditions as in the present study, we demonstrated that cadmium at this concentration $(2 \mu \mathrm{M})$ induced expression of COX-1 and COX-2 only at the mRNA level, but not at protein or enzymatic activity levels [22]. Therefore, one may speculate that other than COX inflammatory pathway(s) might be induced by such cadmium concentrations; for example, lipoxygenase and its product, leukotriene $\mathrm{B}_{4}\left(\mathrm{LTB}_{4}\right)[18,49]$.

It is also possible that the reduction in fatty acid levels by the highest tested cadmium concentration (i.e., $2 \mu \mathrm{M}$ ) might have been due to cell toxicity of cadmium, since in one of our previous studies (employing the same experimental model and experimental conditions), we found significant reduction in THP-1 macrophages viability and increased cell death by apoptosis and necrosis at this cadmium concentration [23]. Maybe the decreased fatty acid concentrations by $2 \mu \mathrm{M} \mathrm{Cd}$ might be the consequence of cadmium-induced, lowered cellular metabolism, and especially, the dysregulated fatty acid/lipid metabolism [50, 51].

In the present study, the degrees of reduction in fatty acid concentrations by cadmium were small (although statistically significant). However, in our opinion, even small alterations in fatty acid levels induced by cadmium (for example, altered MUFA:SFA ratio, altered arachidonic acid level, or altered, disturbed membrane fluidity) might have biological significance. For example, altered MUFA:SFA ratio and altered concentration of PUFA arachidonic acid might have an effect on inflammation $[6,48]$. According to Garcia et al., even slight changes in membrane fluidity may result in aberrant numerous cell functions (e.g., signal transduction or membrane-associated enzymatic activities), leading to some pathological processes [52]. For example, decreased fluidity was demonstrated in erythrocyte ghosts and placental membranes treated with chloride salts of cadmium, mercury, and lead [53, 54]. It is possible that cadmium-induced altered membrane fluidity might affect macrophage adhesion and phagocytic activity [55].
Moreover, despite the fact that cadmium-induced reductions in fatty acid levels were small, the cumulative effect of cadmium after long exposure periods may not be excluded.

In conclusion, cadmium at tested concentrations caused significant alterations in THP-1 macrophage fatty acid levels, disrupting their composition, which might dysregulate fatty acid/lipid metabolism, thus affecting macrophage behavior and inflammatory state.

Open Access This article is distributed under the terms of the Creative Commons Attribution 4.0 International License (http:// creativecommons.org/licenses/by/4.0/), which permits unrestricted use, distribution, and reproduction in any medium, provided you give appropriate credit to the original author(s) and the source, provide a link to the Creative Commons license, and indicate if changes were made.

\section{References}

1. Calder PC (2008) The relationship between the fatty acid composition of immune cells and their function. Prostaglandins Leukot Essent Fatty Acids 79:101-108

2. Zhao G, Etherton TD, Martin KR, Vanden Heuvel JP, Gillies PJ, West SG, Kris-Etherton PM (2005) Anti-inflammatory effects of polyunsaturated fatty acids in THP-1 cells. Biochem Biophys Res Commun 336:909-917

3. Wang Y, Lu J, Ruth MR, Goruk SD, Reaney MJ, Glimm DR, Vine DF, Field CJ, Proctor SD (2008) Trans-11 vaccenic acid dietary supplementation induces hypolipidemic effects in JCR:LA-cp rats. J Nutr 138:2117-2122

4. Blewett HJ, Gerdung CA, Ruth MR, Proctor SD, Field CJ (2009) Vaccenic acid favourably alters immune function in obese JCR:LAcp rats. Br J Nutr 102:526-536

5. Håversen L, Danielsson KN, Fogelstrand L, Wiklund O (2009) Induction of proinflammatory cytokines by long-chain saturated fatty acids in human macrophages. Atherosclerosis 202:382-393

6. Wang S, Wu D, Lamon-Fava S, Matthan NR, Honda KL, Lichtenstein AH (2009) In vitro fatty acid enrichment of macrophages alters inflammatory response and net cholesterol accumulation. Br J Nutr 102:497-501

7. Calder PC (2011) Fatty acids and inflammation: the cutting edge between food and pharma. Eur J Pharmacol 668(Suppl 1):S50-S58

8. Magdalon J, Vinolo MA, Rodrigues HG, Paschoal VA, Torres RP, Mancini-Filho J, Calder PC, Hatanaka E, Curi R (2012) Oral administration of oleic or linoleic acids modulates the production of inflammatory mediators by rat macrophages. Lipids 47:803-812

9. Caspar-Bauguil S, Kolditz CI, Lefort C, Vila I, Mouisel E, Beuzelin D, Tavernier G, Marques MA, Zakaroff-Girard A, Pecher C, Houssier M, Mir L, Nicolas S, Moro C, Langin D (2015) Fatty acids from fat cell lipolysis do not activate an inflammatory response but are stored as triacylglycerols in adipose tissue macrophages. Diabetologia 58:2627-2636

10. Hubler MJ, Kennedy AJ (2016) Role of lipids in the metabolism and activation of immune cells. J Nutr Biochem 34:1-7

11. Lyons CL, Finucane OF, Murphy AM, Cooke AA, Viollet B, Vieira PM, Oldham W, Kahn BB, Roche HM (2016) Monounsaturated fatty acids impede inflammation partially through activation of AMPK. FASEB J 30(Suppl):296.5

12. Lemaitre RN, King IB, Kabagambe EK, Wu JH, McKnight B, Manichaikul A, Guan W, Sun Q, Chasman DI, Foy M, Wang L, Zhu J, Siscovick DS, Tsai MY, Arnett DK, Psaty BM, Djousse L, 
Chen YD, Tang W, Weng LC, Wu H, Jensen MK, Chu AY, Jacobs DR Jr, Rich SS, Mozaffarian D, Steffen L, Rimm EB, Hu FB, Ridker PM, Fornage M, Friedlander Y (2015) Genetic loci associated with circulating levels of very long-chain saturated fatty acids. J Lipid Res 56:176-184

13. Martin-Fuentes P, García-Otín AL, Calvo L, Gómez-Coronado D, Civeira F, Cenarro A (2009) Atorvastatin decreases stearoyl-CoA desaturase gene expression in THP-1 macrophages incubated with oxidized LDL. Lipids 44:115-123

14. Gebauer SK, Chardigny JM, Jakobsen MU, Lamarche B, Lock AL, Proctor SD, Baer DJ (2011) Effects of ruminant trans fatty acids on cardiovascular disease and cancer: a comprehensive review of epidemiological, clinical, and mechanistic studies. Adv Nutr 2:332-354

15. Calder PC (2009) Polyunsaturated fatty acids and inflammatory processes: new twists in an old tale. Biochimie 91:791-795

16. Hemdan NY, Emmrich F, Sack U, Wichmann G, Lehmann J, Adham K, Lehmann I (2006) The in vitro immune modulation by cadmium depends on the way of cell activation. Toxicology 222:37-45

17. Krocova Z, Macela A, Kroca M, Hernychova L (2000) The immunomodulatory effect(s) of lead and cadmium on the cells of immune system in vitro. Toxicol in Vitro 14:33-40

18. Kudo N, Nakagawa Y, Waku K (1996) Biphasic effect of cadmium ions on the secretion of leukotriene B4 in rabbit alveolar macrophages. Arch Toxicol 70:801-808

19. Afolabi OK, Oyewo EB, Adekunle AS, Adedosu OT, Adedeji AL (2012) Impaired lipid levels and inflammatory response in rats exposed to cadmium. EXCLI J 11:677-687

20. Olszowski T, Baranowska-Bosiacka I, Gutowska I, Chlubek D (2012) Pro-inflammatory properties of cadmium. Acta Biochim Pol 59:475-482

21. Liu J, Qu W, Kadiiska MB (2009) Role of oxidative stress in cadmium toxicity and carcinogenesis. Toxicol Appl Pharmacol 238: 209-214

22. Olszowski T, Gutowska I, Baranowska-Bosiacka I, Piotrowska K, Korbecki J, Kurzawski M, Chlubek D (2015) The effect of cadmium on COX-1 and COX-2 gene, protein expression, and enzymatic activity in THP-1 macrophages. Biol Trace Elem Res 165:135-144

23. Olszowski T, Baranowska-Bosiacka I, Gutowska I, Piotrowska K, Mierzejewska K, Korbecki J, Kurzawski M, Tarnowski M, Chlubek D (2015) The effects of cadmium at low environmental concentrations on THP-1 macrophage apoptosis. Int J Mol Sci 6:21410-21427

24. Wang T, Qin L, Liu B, Liu Y, Wilson B, Eling TE, Langenbach R, Taniura S, Hong JS (2004) Role of reactive oxygen species in LPSinduced production of prostaglandin E2 in microglia. J Neurochem 88:939-947

25. Farid NA, Born GS, Kessler WV, Anderson VL (1974) Effect of cadmium on palmitic acid metabolism by rat liver homogenate. $\mathrm{J}$ Pharm Sci 63:1492-1494

26. Kudo N, Nakagawa Y, Waku K (1990) The effect of cadmium on the composition and metabolism of hepatic fatty acids in zincadequate and zinc-deficient rats. Toxicol Lett 50:203-212

27. Kudo N, Nakagawa Y, Waku K (1992) Inhibition of the liberation of arachidonic acid by cadmium ions in rabbit alveolar macrophages. Arch Toxicol 66:131-136

28. Kudo N, Waku K (1996) Cadmium suppresses delta 9 desaturase activity in rat hepatocytes. Toxicology 114:101-111

29. Ramirez DC, Riera CM, Gimenez MS (2001) Modulation of arachidonic acid turnover in macrophages by cadmium. Toxicol Lett 122:9-19

30. Ramirez DC, Gimenez MS (2002) Lipid modification in mouse peritoneal macrophages after chronic cadmium exposure. Toxicology 172:1-12

31. Grawe KP, Pickova J, Dutta PC, Oskarsson A (2004) Fatty acid alterations in liver and milk of cadmium exposed rats and in brain of their suckling offspring. Toxicol Lett 148:73-82
32. Calderoni AM, Oliveros L, Jahn G, Anton R, Luco J, Gimenez MS (2005) Alterations in the lipid content of pituitary gland and serum prolactin and growth hormone in cadmium treated rats. Biometals 18:213-220

33. Alvarez SM, Gomez NN, Scardapane L, Fornes MW, Gimenez MS (2007) Effects of chronic exposure to cadmium on prostate lipids and morphology. Biometals 20:727-741

34. Larregle EV, Varas SM, Oliveros LB, Martinez LD, Anton R, Marchevsky E, Gimenez MS (2008) Lipid metabolism in liver of rat exposed to cadmium. Food Chem Toxicol 46:1786-1792

35. Rogalska J, Brzóska MM, Roszczenko A, Moniuszko-Jakoniuk J (2009) Enhanced zinc consumption prevents cadmium-induced alterations in lipid metabolism in male rats. Chem Biol Interact 177:142-152

36. Konar V, Aydogmus C, Orun I, Kandemir S (2010) The effects of cadmium on fatty acid composition in the muscle and skin of juvenile rainbow trout (Oncorhynchus mykiss, Walbaum 1792). J Anim Vet Adv 9:1191-1196

37. Zhang S, Jin Y, Zeng Z, Liu Z, Fu Z (2015) Subchronic exposure of mice to cadmium perturbs their hepatic energy metabolism and gut microbiome. Chem Res Toxicol 28:2000-2009

38. Auwerx J (1991) The human leukemia cell line, THP-1: a multifacetted model for the study of monocyte-macrophage differentiation. Experientia 47:22-31

39. International Agency for Research on Cancer (2012) Cadmium and cadmium compounds, In: Arsenic, metals, fibres and dusts. A review of human carcinogens. IARC Monogr 100C: 121-145

40. Nandi A, Chandil D, Lechesal R, Pryor SC, McLaughlin A, Bonventre JA, Flynnx K, Weeks BS (2006) Bifenthrin causes neurite retraction in the absence of cell death: a model for pesticide associated neurodegeneration. Med Sci Monit 12:BR169-BR173

41. Folch J, Lees M, Sloane Stanley GH (1957) A simple method for the isolation and purification of total lipids from animal tissues. $\mathrm{J}$ Biol Chem 226:497-509

42. Manual instruction for protein determination using BCA Protein Assay Kit https://tools.thermofisher.com/content/sfs/manuals/ MAN0011430 Pierce BCA Protein Asy UG.pdf. Accessed 13 Feb 2017

43. Cannino G, Ferruggia E, Luparello C, Rinaldi AM (2009) Cadmium and mitochondria. Mitochondrion 9:377-384

44. Dorta DJ, Leite S, DeMarco KC, Prado IM, Rodrigues T, Mingatto FE, Uyemura SA, Santos AC, Curti C (2003) A proposed sequence of events for cadmium induced mitochondrial impairment. J Inorg Biochem 97:251-257

45. Wang Y, Fang J, Leonard SS, Rao KM (2004) Cadmium inhibits the electron transfer chain and induces reactive oxygen species. Free Radic Biol Med 36:1434-1443

46. Steibert E, Kokot F (1981) The effect of cadmium on hepatic fatty acid biosynthesis in rats. In: Gut I, Cikrt M, Plaa GL (eds) Industrial and environmental xenobiotics. Springer-Verlag, Berlin, pp 77-81

47. Kudo N, Nakagawa Y, Waku K, Kawashima Y, Kozuka H (1991) Prevention by zinc of cadmium inhibition of stearoyl-CoA desaturase in rat liver. Toxicology 68:133-142

48. Stryjecki C, Roke K, Clarke S, Nielsen D, Badawi A, El-Sohemy A, Ma DW, Mutch DM (2012) Enzymatic activity and genetic variation in SCD1 modulate the relationship between fatty acids and inflammation. Mol Genet Metab 105:421-427

49. Choi JH, Chang HW, Rhee SJ (2002) Effect of green tea catechin on arachidonic acid cascade in chronic cadmium-poisoned rats. Asia Pac J Clin Nutr 11:292-297

50. Cartularo L, Laulicht F, Sun H, Kluz T, Freedman JH, Costa M (2015) Gene expression and pathway analysis of human hepatocellular carcinoma cells treated with cadmium. Toxicol Appl Pharmacol 288:399-408

51. Go YM, Sutliff RL, Chandler JD, Khalidur R, Kang BY, Anania FA, Orr M, Hao L, Fowler BA, Jones DP (2015) Low-dose 
cadmium causes metabolic and genetic dysregulation associated with fatty liver disease in mice. Toxicol Sci 147:524-534

52. Garcia JJ, Martinez-Ballarin E, Millan-Plano S, Allue JL, Albendea C, Fuentes L, Escanero JF (2005) Effects of trace elements on membrane fluidity. J Trace Elem Med Biol 19:19-22

53. Amoruso MA, Witz G, Goldstein BD (1987) Alterations of erythrocyte membrane fluidity by heavy metal cations. Toxicol Ind Health 3:135-144
54. Boadi WY, Urbach J, Brandes JM, Yannai S (1992) In vitro exposure to mercury and cadmium alters term human placental membrane fluidity. Toxicol Appl Pharm 116:17-23

55. Calder PC, Bond JA, Harvey DJ, Gordon S, Newsholme EA (1990) Uptake and incorporation of saturated and unsaturated fatty acids into macrophage lipids and their effect upon macrophage adhesion and phagocytosis. Biochem J 269:807-814 